\title{
La traducción científico-técnica: aportaciones desde los estudios de traducción ${ }^{1}$
}

\section{(Scientific and Technical Translation: Contributions from Translation Studies)}

Javier Franco Aixelá ${ }^{2}$

Universidad de Alicante, España

\begin{abstract}
resumen
Tradicionalmente, la traducción científico-técnica ha contado poco en la reflexión tanto lingüística como traductológica por partir de un lenguaje escasamente creativo. Hasta las últimas décadas del siglo xx los investigadores no comienzan a prestarle verdadera atención. En este trabajo se analizan las aportaciones de los estudios de traducción modernos a esta modalidad de transferencia interlingüística. La traductología se desarrolla a partir de una perspectiva textual y se vuelca sobre la optimización del texto meta, como un instrumento de comunicación semiautónomo que debe encajar en un nuevo sistema de expectativas y convenciones. Se presta atención a dos aspectos de la traducción: la interferencia y la posibilidad de mejora del texto original.
\end{abstract}

\section{abstract}

Traditionally, scientific and technical translation has been given less importance in linguistic and translatological research because it uses a variety of language which is barely creative. Until the last decades of the $20^{\text {th }}$ century, researchers had not given it real attention. The main contributions made by

1 Elaborado con base en la ponencia presentada por el autor en el IV Congreso Internacional de Lingüística Aplicada, llevado a cabo en mayo de 2013, en el Campus Omar Dengo, de la Universidad Nacional de Costa Rica. Recibido: 19 de agosto de 2012; aceptado: 13 de enero de 2013.

2 Correo electrónico: Javier.Franco@ua.es 
modern translation studies are analyzed in this paper. Translation studies takes a textual stance and focuses on optimizing the target text, which is understood as a semi-autonomous communication tool that must fit into a new system of expectations and conventions. Two other translation issues are also addressed here: interference and the possibility of improving the source text.

Palabras clave: traducción científico-técnica; terminología; investigación; interferencia. mejora.

Keywords: scientific and technical translation; terminology; research; interference. improvement.

\section{Introducción: la importancia de la traducción científico-técnica}

Para empezar, nada mejor que intentar perfilar de qué estamos hablando. Esto de los géneros parece muy evidente a primera vista, pero, como todo, se complica en cuanto uno escarba un poco. La razón principal de esta complicación radica en que nos empeñamos en encerrar en categorías cerradas lo que no deja de ser una realidad porosa y variable. Hace cuarenta años, cuando uno escribía en España una instancia, era preciso incluir formulismos como «Dios guarde a usted muchos años» 0 «Su seguro servidor». Ahora todo el mundo se reiría de nosotros si lo hiciéramos así. Por si fuera poco, las características de los géneros no sólo cambian con el paso del tiempo, sino que con mucha frecuencia, en cuanto nos salimos de tipos textuales muy definidos como pueda ser un prospecto o una partida de nacimiento, ni siquiera son demasiado estables ni siempre iguales a sí mismos. En el género artículo científico, por ejemplo, hay múltiples rasgos que dependen mucho de la perspectiva del autor y de la cultura a la que pertenece. Si uno es latino, tenderá más a estructuras sintácticas relativamente complejas y a utilizar un lenguaje más tecnificado o esotérico para demostrar el dominio del tema. Pero incluso perteneciendo a la «misma» cultura y a la «misma» disciplina, como podrían ser los estudios de traducción por ejemplo, el lenguaje utilizado dentro del mismo género 
por un autor postestructuralista, con su pasión por los juegos de palabras, tiene poco que ver con el que usaría un descriptivista, con su pasión por la búsqueda de una perspectiva más o menos objetiva y por la transparencia discursiva.

Como sucede con tantos otros géneros, los textos científicotécnicos (TCT) son de difícil caracterización y dada su enorme variedad temática y tipológica no cabe una definición simple que los abarque. Los dos rasgos más visibles y que probablemente constituyen los marcadores intuitivos por los que afirmamos que un texto es científico-técnico son la temática y la terminología. Sin embargo, un discurso político de la ministra de sanidad sobre sus proyectos de gestión en atención primaria tendría un tema claramente médico, pero ninguno de nosotros diríamos que constituye un TCT. Igualmente, una novela de ciencia ficción típica contendrá probablemente más términos especializados, reales o inventados, que un artículo de revista científica y tampoco nadie diría que se trata de un TCT.

La cosa es más compleja. En esencia, cabe afirmar que los TCT son textos caracterizados por una combinación de rasgos, entre los que destaca que exista una disciplina asentada que les sirva como marco comunicativo, que su autor sea un especialista, una estructuración rígida, una progresión temática sistemática, una presencia visible de terminología especializada, tendencia a la simplificación sintáctica y un tenor claramente formal. Ejemplo arquetípico de un texto científico son los ensayos académicos como este que ahora comienzo a desarrollar aquí ante ustedes, caracterizados por un intento de profundizar y cuestionar el conocimiento existente. Por su parte, los textos puramente técnicos serían aquellos caracterizados por su voluntad de aplicabilidad, entre los que los manuales de instrucciones constituyen el caso más prototípico.

Los textos científico-técnicos y su traducción son la cenicienta de la investigación tradicional tanto en lingüística como en traducción, como se refleja en el hecho de que apenas fueran objeto de interés académico en el pasado (cf. Franco Aixelá, 2004). Esto se 
debe fundamentalmente al hecho de que el tipo de lenguaje utilizado en este tipo de textos se suele considerar escasamente creativo $\mathrm{y}$, por lo tanto, de poco interés para los investigadores, que en las áreas relacionadas con la lengua han preferido dedicar su tiempo a retos supuestamente mayores, como el estudio de los grandes autores literarios y la Biblia. De hecho, hay autores tan importantes como Schleiermacher ${ }^{3}$ que llegan incluso a negarle a la traducción científico-técnica la condición de «verdadera traducción», mientras que Ortega y Gasset ${ }^{4}$ plantea este tipo de traducción como excepción parcial a la intraducibilidad esencial entre las lenguas que él postula, siempre amparándose en el supuesto carácter artificial del lenguaje científico-técnico, donde sí sería al menos parcialmente posible que la traducción consistiese en una mera sustitución de cada término por su equivalente exacto.

Una de las consecuencias más importantes de los estudios de traducción modernos ha consistido en contribuir a problematizar la cuestión de los géneros al mismo tiempo que, paradójicamente, se buscaban definiciones estables que permitieran a los traductores trabajar con plantillas claras. La teoría tiene la mala costumbre de subrayar la complejidad de la realidad, algo con lo que los teóricos casi se podría decir que disfrutan. Con todo, la complejidad también tiene sus ventajas. Así, esta misma problematización ha traído consigo una atención mucho mayor a lo que antes se tendía a despreciar como lenguaje básicamente previsible y artificial, sin mayor interés investigador. En este sentido la primera y fundamental aportación teórica de los estudios de traducción al estudio de los textos científico-técnicos ha consistido en su dignificación como objeto de estudio y, por derivación, en su dignificación como actividad profesional mucho más rica y compleja de lo que se creía en el pasado.

$3 \quad$ Friedrich DanielErnst Schleiermacher, Über die verschiedenen Methoden des Übersetzens (1813). Cit. por la versión española de Valentín García Yebra: «Sobre los diferentes métodos de traducir», Filología Moderna (1978): 343-392.

4 José Ortega y Gasset, «Miseria y esplendor de la traducción», La Nación de Buenos Aires, 1937 (mayo-junio). 
En efecto y afortunadamente, las cosas están cambiando y en la actualidad, este tipo de traducción concita uninterés creciente.Por dar una cifra ilustrativa, en la década de los noventa tenemos identificados en la base de datos bibliográfica bitra ${ }^{5}$ más de mil estudios centrados en algún aspecto de la traducción técnica y científica, lo que supuso un poco más del $10 \%$ de todo lo que se publicó sobre traducción einterpretación para dicha década. El aumento de interés quedará especialmente claro si comparamos ese $10 \%$ de los años noventa con el $1 \%$ de interés que suscitaba la traducción científicotécnica durante la primera mitad del siglo xx.

Más allá de la legítima selección de intereses investigadores por parte de cada cual, la situación es objetivamente injusta y poco inteligente por varias razones, entre las que destaca la enorme importancia de este tipo de textos en el mundo, con la traducción a la cabeza del flujo de información tanto entre investigadores como entre especialistas y el público lego. Dicha relevancia no se limita ni mucho menos al mundo moderno. Por poner un ejemplo especialmente ilustrativo, es de sobra conocido que el canon científico del mundo occidental se basa en autores como Aristóteles, que establecieron el marco básico que da sentido al método científico y a las grandes preguntas que la humanidad continúa planteándose hoy en día. Pues bien, la importancia de la traducción al respecto no se limita únicamente al hecho de que la inmensa mayoría de nosotros no podríamos leer a Aristóteles en griego clásico, sino a algo menos conocido y probablemente más trascendental, como es el hecho de que los escritos originales de Aristóteles sencillamente no existen. $\mathrm{Al}$ igual que numerosos otros autores de la antigüedad, la obra «original» de Aristóteles se perdió a los pocos años de su muerte, de tal manera que su legado únicamente existe en forma de traducción o comentario, que no deja de ser otra modalidad de traducción.

5 Javier Franco Aixelá (ed.), BITRA (Bibliografía de Interpretación y Traducción). 2001-2013; $<$ http://dti.ua.es/en/bitra/introduction.html>. 
Este simple hecho obliga a replantear la visión tradicional de la traducción como una mala copia que irremisiblemente daña al original. Si Aristóteles sólo existe en versión traducida, entonces la traducción se convierte de manera objetiva y necesaria en la tabla de salvación sin la cual sus ideas no podrían sobrevivir. Pasamos así de una imagen en la que la traducción mata a otra en la que da nueva vida, algo bastante más cercano a la realidad y, ya que estamos, algo que dignifica también a nuestra profesión, haciendo que pasemos de ser asesinos a vivificadores de la palabra.

Resulta difícil exagerar la importancia de la traducción científico-técnica. Para ilustrar este punto, debería bastar con recordar algo tan obvio como que de no existir la traducción, el ser humano se vería casi inevitablemente obligado a volver a inventar la rueda una y otra vez por desconocimiento de los descubrimientos ya realizados en las demás culturas. Evidentemente, una situación de esta naturaleza resulta casi inimaginable, especialmente por encontrarse en las antípodas del vertiginoso intercambio de información que caracteriza al mundo moderno.

\section{Sobre la necesidad de estudiar la traducción científico-técnica}

Pese a lo dicho anteriormente, es cierto que la importancia de este tipo de traducción no constituye un argumento que en sí mismo respalde la necesidad de dedicarle más esfuerzos investigadores de los necesarios. Aunque siempre permanecería la necesidad de llevar a cabo estudios históricos que nos sirvieran para analizar el flujo de entradas y salidas de las ideas en cada cultura con el fin de comprender cómo circula el conocimiento, si realmente todo resultase tan simple y mecánico como dan a entender los autores antes mencionados, el estudio de la traducción científico-técnica podría reducirse a fijar dos aspectos esenciales de una vez por todas y dejar la cuestión tranquila porque no daría para más. Me refiero a la elaboración de glosarios sistemáticos en los que supuestamente apareciesen los 
equivalentes prefijados de cada término especializado y a la elaboración de plantillas que reflejasen las características estructurales y estilísticas de cada una de las decenas de subgéneros que constituyen el amplísimo campo de lo científico-técnico.

En cuanto a los glosarios terminológicos, son de hecho múltiples los intentos de elaborar diccionarios especializados, muchos de ellos en línea, y el sueño de todo aprendiz de traductor consiste en que la mera consulta de esos diccionarios pueda resolver todas sus dudas terminológicas. Por supuesto y por desgracia para las ilusiones del futuro traductor, el despertar es rápido, nada más asistir perplejo a las listas descontextualizadas de supuestos sinónimos que aparecen al consultar casi cualquier entrada de un diccionario técnico mínimamente exhaustivo. Cuando uno debe traducir un término y se encuentra con media docena de posibilidades entre las que tiene que elegir sin apenas pistas, empieza a comprender por qué la vida del traductor es dura.

Por poner un ejemplo ilustrativo, el término epidemiológico inglés odds ratio, omnipresente en los textos de investigación médica, posee, que yo sepa, un mínimo de siete propuestas distintas de traducción: razón de productos cruzados, razón de disparidad, razón de predominio, proporción de desigualdades, razón de oposiciones, oposición de probabilidades contrarias, cociente de probabilidades relativas y oportunidad relativa. Curiosamente, ninguna de ellas suele utilizarse en español médico, que prefiere la versión inglesa a modo de extranjerismo. Así, a estas listas descontextualizadas se añade el hecho de que resulta perfectamente posible que ninguna de las supuestas equivalencias propuestas por el diccionario de turno sirva para nuestro propósito. Como consecuencia, el descubrimiento de que la terminología es todo menos una serie de repertorios biunívocos constituye el primer contacto con la compleja realidad de la traducción científico-técnica. En ese sentido, la terminología clásica no dejaba de presentar la biunivocidad (un solo término para cada referente y un único referente por cada término) como si fuese 
una realidad de los tecnolectos con algunas excepciones. Afortunadamente el enfoque descriptivista moderno es también en la terminología cada vez más consciente de que esto no es así (cf., por ejemplo, Cabré Castellví6).

$\mathrm{Si}$ aceptamos que la nomenclatura científico-técnica es todo menos biunívoca, nos encontramos con una pregunta esencial que la terminología, pese a reconocer la situación, no resuelve para los traductores y con respecto a la cual resulta fundamental llevar a cabo investigación sistemática que nos ayude a entender el problema: cuáles son las respuestas habituales de los traductores y cuáles las causas, ventajas y desventajas de cada una de las posible soluciones. La terminología puede, ciertamente, ayudar explicándonos la conveniencia de la coherencia terminológica y cómo se construyen idealmente términos, especialmente neologismos, pero con esa información y consejos no basta para algo tan fundamental como elegir con conocimiento de causa la opción más adecuada en cada caso, especialmente en lo que se refiere al encendido debate entre el uso, defendido por los denominados «frecuentistas» y la ortodoxia lingüística, apoyada por los denominados «puristas», una cuestión que desarrollaré más adelante.

Igualmente relevante es dejar constancia de que la idea de que realizar traducción científico-técnica consiste básicamente en traducir terminología es otro gran cliché que no se sostiene en pie. Al contrario, lo cierto es que en un texto técnico prototípico, la presencia de terminología raramente supera el 10-20 \% (cf. Newmark 19817). El grueso de un texto técnico o científico está constituido por lenguaje general, normalmente de tenor formal, sobre el que por razones obvias la moderna ciencia terminológica tiene más bien poco que decir. Por el contrario, el dominio de la traducción de los lenguajes

6 María Teresa Cabré Castellví, La terminologia: la teoria, els mètodes, les aplicacions (Barcelona: Empúries, 1992). [Existe versión española de Carles Tebé: La terminología: teoría, metodología, aplicaciones (Barcelona: Antártida, 1993).]

7 Peter Newmark, Approaches to Translation (Oxford: Pergamon Press, 1981). 
no especializados es un campo de investigación específico de los estudios de traducción.

$\mathrm{Al}$ respecto, uno de los estudios pendientes más interesantes consiste en el muy distinto tratamiento de la cuestión de la sinonimia entre el ámbito terminológico y el del lenguaje general, siempre dentro de los textos científico-técnicos. Así, en el caso de la terminología, evitar la sinonimia constituye una suerte de mandato universal en la actualidad, mientras que en el ámbito del lenguaje general que la rodea se trata de una cuestión variable y estrechamente ligada a las tradiciones culturales de cada sociedad. En la cultura española peninsular, por ejemplo, se considera que la repetición léxica para el vocabulario general constituye una muestra de pobreza estilística, mientras que en inglés sucede todo lo contrario y el objetivo en este idioma consiste en primar las variantes más sencillas, apostando por la claridad en lugar de la variedad. Esto se ve claramente en el uso de los verbos copulativos. Donde en inglés se produce una repetición del verbo be como nexo de unión sistemático, en español se cultiva metódicamente la sinonimia y los textos científico-técnicos en este idioma nos presentarán unos cuantos ser/estar acompañados de multitud de variantes como constituir, radicar, suponer o consistir.

Se trata de una cuestión de práctica textual que no suele verse reflejada en los estudios terminológicos, ya que excede a su ámbito de estudio. Y he aquí otra aportación de los estudios de traducción modernos: el afloramiento de nuevos objetos de estudio hasta ahora ignorados de manera casi universal.

Otras situaciones con usos sistemáticamente distintos entre ambos idiomas y necesitadas de reflexión desde el punto de vista de los estudios de traducción son la repetición de otros verbos comodín como have, la longitud de los periodos (frases más largas en español), la frecuencia de la subordinación (mayor en español), la diferencia de registro (más formal en español en muchos géneros), la importancia relativa del estado de la cuestión (normalmente más extensa en español), el uso de siglas y abreviaturas (mayor en inglés), los 
elementos culturales específicos (de tratamiento claramente diferenciado en los géneros más técnicos), los nombres propios (con mayor tendencia a la repetición en este tipo de textos), el modo de cultivar la cortesía lingüística (¿should se traduce mejor como «debería»o como «debe» o ninguna de las dos?), los aspectos ideológicos (subject no tiene las mismas connotaciones éticas como «sujeto» o como «paciente»), la interferencia (¿es siempre negativa?) o la posibilidad de mejora en el proceso de traducción (que es frecuente, pero la mayor parte de las veces inconsciente o silenciada).

Se trata en todos los casos de cuestiones básicamente ajenas a la terminología porque se escapan a su terreno de actuación. Sin embargo, son elementos trascendentales que afectan a la mayor parte de los textos científico-técnicos que tenemos que traducir y que precisan de una atención especial por parte de los estudios de traducción. Para ello, es preciso trascender la tendencia a centrarse en cuestiones individuales de terminología y macroestructuras contrastivas, que sin duda son también necesarias, pero insuficientes. O, por decirlo con otras palabras, el necesario estudio de los árboles más visibles no debe impedirnos examinar ni el sotobosque ni el propio bosque en su conjunto.

Aquí quisiera trazar unas cuantas pinceladas sobre los dos últimos aspectos necesitados de investigación que acabo de mencionar: las causas y la gestión de la interferencia, así como la posibilidad de mejora del texto original. Ambos constituyen facetas de la traducción científico-técnica que se encuentran bajo una importante losa de clichés sociales acríticos que, desde mi punto de vista, resultan muy perjudiciales para los traductores, sobre todo porque coartan sus impulsos hacia la eficacia comunicativa del texto final. Además, los dos constituyen áreas en las que los análisis terminológicos o bien directamente renuncian a entrar (la cuestión de la mejora) o bien tienden a realizar análisis descontextualizados que con frecuencia no casan bien con la práctica profesional de la traducción (la cuestión de 
la interferencia), lo que los sitúa en el centro mismo del asunto que quería tratar en esta exposición.

\section{La interferencia}

La interferencia constituye una curiosa combinación de práctica universal $\left(\right.$ Toury $^{8}$ ) y fenómeno vilipendiado en traducción (la gran mayoría de los autores la condenan de forma más o menos rotunda, especialmente desde un punto de vista terminológico).

Cabría definir la interferencia como la importación en el texto meta de elementos léxicos, sintácticos, culturales o genéricos típicos del sistema semiótico original y poco frecuentes o inexistentes en el contexto meta, al menos en calidad de usos originales de comunicación en la lengua correspondiente. Esta definición incluye la importación, ya sea intencionada o no, de palabras, términos o expresiones (interferencia léxica), de estructuras microtextuales (interferencia sintáctica), elementos culturales específicos (interferencia cultural, nombres propios incluidos) o de convenciones genéricas relacionadas con la macroestructura del texto.

Teniendo en cuenta que la importación de nombres propios forma parte de la interferencia, esta se encuentra muy presente en cualquier texto traducido por definición, especialmente en los géneros científico-técnicos, en los que existe una fuerte tendencia a traducir por repetición incluso los nombres propios expresivos, es decir, aquellos que aportan información sustancial sobre el referente al que designan, como sucede por ejemplo con los nombres de estudios que se citan con mucha frecuencia en los ensayos científicos.

Así pues, la mala reputación de este fenómeno se circunscribe en realidad a lo que aquí hemos denominado interferencias léxica y sintáctica, que son las que afectan a las nomenclaturas propias y a la estructuración de las oraciones. Es aquí donde los estudios de raíz terminológica

8 Gideon Toury, «Interlanguage and its Manifestations in Translation», In Search of a Theory of Literary Translation (Tel Aviv: The Porter Institute, 1978) 71-78. 
se dedican una y otra vez a desaconsejar o criticar duramente cualquier opción que se aparte de los usos respetuosos con la pureza de la lengua meta, muy especialmente a la hora de crear neologismos, lo que constituye uno de los deberes más específicos del traductor científicotécnico. Por citar algún ejemplo del enfoque con el que se suele abordar esta cuestión, he aquí fragmentos de tres resúmenes de artículos sobre la interferencia en los textos científico-técnicos que creo que resultan representativos de la actitud de una buena parte de los que abordan este tema y del discurso social dominante alrespecto:

Los peligros para el español se agravan en la época actual, especialmente en los neologismos técnicos y científicos $\left(\right.$ Lapesa $\left.^{9}\right)$.

[...] la continua incorporación de anglicismos al lenguaje científicomédico que practicamos constituye una de las mayores dejaciones culturales de nuestro tiempo, a la que tenemos que poner coto cuanto antes si no queremos que la invalidez de nuestra lengua sea la expresión formal de una cultura sin respeto ni respaldo ${ }^{10}$.

En este artículo analizamos la presencia del inglés en textos meta en español tras haber experimentado el proceso de traducción y cómo sutiles estructuras sintácticas y convenciones pragmáticas se transfieren al español a través de textos técnicos mal traducidos ${ }^{11}$ (traducción y énfasis míos; el resumen original puede consultarse en bitra).

Ante este tipo de condenas sin demasiados matices, lo que plantea la escuela descriptivista en traducción es la necesidad de al menos tratar de entender la realidad antes de juzgarla. Como bien se afirma

9 Rafael Lapesa, «La necesidad de una política hispánica sobre neologismos técnicos y científicos», Telos 5 (1986): 84-89.

10 Antonio Campos Muñoz, «La salud y la palabra», Panace@ 2, 6 (2001): 2-3; <http://www. medtrad.org/panacea.html>.

11 María Jesús Rodríguez Medina, «Modalidades de la traducción profesional en el campo de la informática», Isabel Pascua Febles (ed.), La traducción. Estrategias profesionales (Las Palmas de Gran Canaria: Universidad de Las Palmas de Gran Canaria, 2002) 181-192. 
en muchos estudios de traducción, también en algunos de los más beligerantes contra la importación de elementos extranjeros, la interferencia no es ninguna novedad y la propia presencia masiva y continuada de términos de origen grecolatino en nuestros tecnolectos constituye buena prueba de ello. Intentemos, entonces, trazar algunas causas probables de la interferencia en traducción técnico científica con la intención de entender el comportamiento de los traductores.

Sin duda, la incompetencia, entendida como el comportamiento involuntario de parte de los traductores que por falta de formación o de tiempo para revisar sencillamente se dejan arrastrar de manera inconsciente por el texto original, forma parte de la explicación. Sin embargo, reducir el fenómeno de la interferencia a una cuestión de falta de profesionalidad nos deja ante la tesitura de admitir que, dado que la interferencia es un universal de traducción, todos los traductores son incompetentes, a lo que habría que añadir que la inmensa mayoría de sus lectores y editores también lo son, puesto que no sólo aceptan alegremente textos con interferencias de todo tipo, sino que incluso llegan a exigirlas. En este sentido, son reveladoras las quejas de traductores formados en nuestras universidades que, como ya dijo hace mucho tiempo Neubert ${ }^{12}$, precisamente por hacer caso de profesores que defendían la pureza del idioma a ultranza y que, al ser «demasiado puros» en su uso de la lengua meta, se encuentran con el rechazo de los clientes porque tanta pureza resulta ser contraria a los usos aceptados en el género científico-técnico correspondiente. Debe, pues, haber otras razones sólidas suplementarias a la posible incompetencia que justifiquen la aceptación y hasta la preferencia por este fenómeno entre traductores, editores y usuarios de los textoscientífico-técnicos.

Veamos algunas de ellas, parte de las cuales no suelen aparecer mencionadas en el discurso terminológico habitual. Nos referimos a: 1) la doble tensión intrínseca en traducción; 2) la creación de un tecnolecto propio que consolide la identidad de grupo; 3 ) la inexistencia

12 Albrecht Neubert, «The Impact of Translation on Target Language Discourse Text vs. System», Meta 35, 1 (1990): 96-101; 〈http://www.erudit.org/revue/meta/>. 
de un término o estructura dados en lengua meta; 4) el prestigio que pueda añadir al texto la presencia explícita de la cultura de procedencia; y 5) La especial disponibilidad terminológica de las variantes extranjeras derivada del uso sistemático de la lengua franca en la comunicación científica.

Empecemos pues por la doble tensión. Para entender la interferencia, creo que lo primero que hay que considerar es la naturaleza intrínsecamente dual de la traducción, que en términos de Toury se debate entre ser como «el» original y como «un» original. Por supuesto, ser como «el» original potencia la idea de reproducción de los elementos presentes en el original, lo que implica interferencia. Por su parte, ser como «un» original implica evitar fórmulas y recursos aplicados en el texto original para tratar de construir la traducción a partir de modelos óptimos escritos originalmente en lengua meta. La traducción se ve por tanto sometida a tensiones centrípetas y centrífugas que se contradicen y entre las cuales el traductor busca siempre un equilibrio, muchas veces claramente inclinado hacia uno de los dos polos, pero sistemáticamente incapaz de anular por completo la presencia de la fuerza contraria. Por lo demás, la fuerza centrípeta (la que potencia la interferencia) se ve reforzada por un estímulo muy poderoso, la denominada economía en el esfuerzo. En circunstancias profesionales de mucho estrés - como sucede con frecuencia por los breves plazos y bajas tarifas dominantes en la profesión-, la traducción conservadora resulta preferible por su mayor sencillez y agilidad, ya que no exige detenerse a buscar alternativas a las equivalencias más evidentes por cercanas al texto original. A este último respecto, quizá convenga recordar aquí que hasta la aparición de los estudios de traducción modernos nadie introdujo nunca las condiciones laborales como una parte esencial de cualquier estudio sobre el comportamiento de los traductores.

He formulado la segunda gran razón de la interferencia como el interés de los colectivos humanos por crear una identidad de grupo. Nada es más eficaz para ello que poseer un tecnolecto propio, que cumple dos funciones simultáneamente: necesidad y exclusividad. 
En cuanto a la necesidad, la búsqueda de exactitud comunicativa constituye una lógica constante en cualquier desempeño técnico o científico. El término «babor» es necesario porque no es relativo, mientras que «izquierda» sí lo es. Encontrarse en plena tempestad discutiendo si las indicaciones del capitán se refieren a su izquierda o la del marinero que debe cumplir una orden no sería muy buena idea. Además, la existencia de una nomenclatura propia sirve para reforzar la identidad del grupo que la utiliza, porque ayuda de manera determinante a separarlo del resto de las personas. Se trata de algo intrínseco a la dinámica de grupos con un interés común y específico suficientemente sólido y diferenciado, desde los adolescentes hasta los informáticos, pasando por los presidiarios y los estudiosos de la traducción y la interpretación. En lo que se refiere a su relación con la interferencia, resulta por supuesto mucho más sencillo acuñar términos nuevos a partir de los presentes en textos extranjeros que tener que construir una terminología propia a partir de la nada, eso sin contar con que el exotismo de los términos de origen extranjero aporta un plus de exclusividad porque ayuda a que el tecnolecto resulte más opaco para los legos. Una vez más, la economía en el esfuerzo nos ayuda de manera determinante a comprender la aceptabilidad e incluso las preferencias hacia el fenómeno de la interferencia, en este caso por parte de los especialistas en un área determinada.

La tercera gran razón para la interferencia radica en la inexistencia de un término o estructura dados en lengua meta. Se trata quizá del único motivo que los terminólogos sí mencionan de manera sistemática en sus escritos, aunque con tendencia a promover la creación de neologismos basados en recursos preexistentes en lengua meta, en lugar de adoptar la propuesta presente en el idioma extranjero. Sin embargo, normalmente no son los terminólogos los que deciden el formato de los neologismos, sino los traductores y los especialistas en los diversos campos, que a través de sus escritos van introduciendo los neologismos con una clara tendencia a seguir muy de cerca los términos extranjeros porque resultan así 
más sencillos de crear y además contribuyen con su formato exótico a reforzar la identidad diferenciada del grupo a cuyo repertorio se incorpora el término.

El cuarto motivo que dábamos para explicar la interferencia era el prestigio de la cultura de origen, que se manifiesta de manera especialmente visible a través de su lengua. Al igual que los anteriores, no se trata de un fenómeno en absoluto nuevo. Como es bien sabido, buena parte de los términos técnicos y científicos existentes en las lenguas occidentales son de origen grecolatino, muchos de ellos introducidos gracias a la traducción desde hace muchos siglos. En este sentido, resulta curioso que los terminólogos continúen aconsejando la creación de neologismos a partir de la interferencia grecolatina, pero rechacen por principio esto mismo cuando la etimología es anglosajona. La razón que se suele dar para ello es doble: que la tradición ha sancionado este uso y que constituyen recursos especialmente transparentes por ser las raíces grecolatinas bien conocidas de antemano por todos los especialistas. Ambas son sin duda razones sólidas, pero al mismo tiempo no deja de ser una admisión de la conveniencia de utilizar mecanismos de la odiada interferencia para la introducción de terminología novedosa.

Lo cierto es que en la historia de la humanidad siempre ha habido sociedades situadas en vanguardia y en posición hegemónica en los terrenos político, militar, económico y científico. Para desgracia de los usuarios de lenguas romances, hace ya algún tiempo que ninguno de nuestros idiomas ocupa esta posición, por lo que una consecuencia lógica y hasta imparable es la preeminencia actual del inglés, que se ve probablemente reforzada por la velocidad vertiginosa con la que el conocimiento científico fluye en la época de la globalización. En este sentido, existen ya áreas como la de símbolos, siglas y abreviaturas en las que la conveniencia de internacionalizar (globalizar) el lenguaje científico ha impuesto una clara preferencia por la repetición en traducción, una tendencia que cada vez encuentra menor resistencia. 
En lo concerniente a la globalización, debemos tener también en cuenta nuestro quinto motivo para la interferencia: la familiaridad de los expertos con la lengua franca, que los no anglosajones utilizan de manera cada vez más sistemática para comunicarse más allá de sus fronteras. Como sucedía en la Edad Media o el Renacimiento con el latín, son cada vez más los investigadores y especialistas que leen, publican y se comunican con sus colegas extranjeros directamente en inglés, lo que ayuda a explicar aún mejor la atracción de la fuerza centrípeta a la que hacíamos referencia al principio de este apartado. Si la terminología anglosajona se convierte en un uso habitual en el discurso científico-técnico de los especialistas cuya lengua materna no es la inglesa, nada más natural que la preferencia por el uso de términos extranjeros también cuando se comunican en su propio idioma. Se trata de un mecanismo especialmente cómodo cuando intercambian ideas con sus pares, sin importar de qué idioma sean hablantes, puesto que son igualmente conocedores de esas variantes terminológicas inglesas asociadas a su disciplina, variantes con frecuencia mucho más sólidamente ancladas en su tecnolecto que los intentos de creación de terminología local alternativa.

Como se ha podido ver en esta sección, la interferencia constituye como mínimo un fenómeno multifacético y complejo que, salvo incompetencia manifiesta del traductor, no se puede resolver con una simple condena global. Por el contrario, el enfoque descriptivista procedente de los estudios de traducción nos ayuda a entender las motivaciones más profundas que subyacen a este universal de traducción y a su aceptabilidad e incluso preferencia entre gran parte de los especialistas y traductores.

En el fondo, el debate sobre la corrección o conveniencia del uso de variantes derivadas de la interferencia se centra entre dos enfoques comunicativos claramente diferenciados, ambos con posturas defendibles: el frecuentismo y el purismo, por utilizar los términos con que ambos se califican mutuamente de manera crítica. Los frecuentistas defienden la prioridad del objetivo comunicativo de la traducción, 
para lo que se basan en la máxima de Quintiliano (c. 95 d. C.), según la cual «consuetudo certissima est loquendi magistra» (el uso es el gran maestro del habla). Si para garantizar claridad y precisión es necesario recurrir a la interferencia por ser este el origen de la variante más usada y mejor conocida por el lector tipo, bienvenida sea. Los puristas, por el contrario, defienden ante todo la corrección lingüística, entendida como el máximo respeto a las tradiciones, normas y potencialidades de la lengua meta. Para ellos, siempre es preferible utilizar o partir de recursos previamente existentes en la lengua meta, aunque ello suponga nadar contra corriente y elegir una variante en principio más extraña u oscura para el receptor. Ambos polos, como casi siempre sucede, suelen matizarse en la realidad, de tal modo que la mayoría de los frecuentistas preferirán la variante más respetuosa con la lengua meta cuando esta presente un nivel de frecuencia y de claridad comparables a la variante de origen extranjero, mientras que la mayoría de los puristas están dispuestos a reconocer que hay numerosos casos en los que recurrir a variantes nativas constituye una batalla perdida de antemano debido al alto grado de opacidad que ello acarrearía frente a variantes extranjeras aceptadas por todos. Así, no conozco a ningún traductor purista que se niegue a utilizar términos como «ciencia ficción», pese a constituir un anglicismo cuya construcción es manifiestamente contraria a todas las reglas del español y, de igual manera, la inmensa mayoría de los frecuentistas conscientes de los usos lingüísticos prefieren ADN en lugar de DNA, siendo ambas variantes igualmente transparentes y precisas.

Quizá lo más importante de estas reflexiones que acabo de presentar radique en que se comprenda como legítimo que la preferencia consciente y voluntaria por variantes producto de la interferencia no tiene por qué indicar incompetencia por parte del traductor. Puede por supuesto ser discutible y son muchos los estudiosos que opinan que la interferencia es una mala idea casi por definición. Sin embargo, desde el punto de vista de la realidad profesional, en los textos científico-técnicos escritos originalmente en lengua no inglesa 
se suele dar prioridad a esta opción y, como hemos visto, no es rara la situación en la que un traductor recién graduado se encuentra ante la paradoja de que ha traducido un texto técnico evitando cuidadosamente (casi) toda interferencia, tal como le ha enseñado su profesor purista, y el cliente rechaza el texto o insiste en incorporar los términos ingleses descartados «porque así es como lo decimos nosotros y así es como lo entenderán y aceptarán mejor los lectores». La cuestión de la interferencia constituye de hecho un asunto apasionante en el plano didáctico, en el que los docentes nos vemos una y otra vez obligados a optar entre nuestras preferencias lingüísticas personales y una realidad profesional terca, que en muchas ocasiones prefiere opciones distintas de las supuestamente ideales desde el punto de vista de respeto a la naturaleza y reglas de la lengua meta.

A continuación, abordaremos la posibilidad de mejora del texto original, otra cuestión espinosa que sólo se aborda desde la perspectiva de los estudios de traducción, ya que la ciencia terminológica no suele contemplar la posibilidad de que el original esté sencillamente mal escrito.

\section{La mejora}

En esta última sección de mi análisis quisiera destacar el papel que desempeña el traductor en este tipo de textos, para lo que resulta especialmente conveniente cuestionar tres mitos que lastran nuestra labor. Dos de ellos están muy relacionados entre sí y ya los hemos comentado más arriba: el de la traducción técnico científica como labor mecánica y el que indica que traducir este tipo de textos consiste fundamentalmente en procesar terminología.

Aparte de reubicar la traducción científico-técnica, otorgándole el carácter también creativo que de hecho posee, existe un tercer mito que resulta necesario cuestionar si deseamos entender la dinámica real de la traducción, muy especialmente en lo tocante a este tipo de textos. Me refiero al mito de la perfección intrínseca 
de los originales, una creencia que hemos heredado del movimiento romántico, que la llevó a su máxima expresión.

Tangencialmente, conviene comentar aquí que este mito, unido al de Babel, ha acarreado uno de los lastres más pesados que hemos tenido que arrastrar los traductores desde hace siglos: la idea de que una traducción debe ser necesariamente peor que su original, que nuestro trabajo consiste exclusivamente en reducir pérdidas inevitables y que nunca seremos capaces de producir más que pálidas sombras de originales maravillosos. Vista así, la nuestra sería una profesión deprimente, condenada a la mediocridad y a la producción de falsificaciones de baja calidad. Tan fuerte ha llegado a ser el mito que incluso uno de los instrumentos del conocimiento más reputados en el mundo entero, la Encyclopaedia Britannica, todavía afirma en marzo de 2013 que una traducción tiene que ser peor que su original y que, si no lo es, entonces ya no merece el verdadero nombre de traducción, sino que se trata de una «obra nueva, derivada del original, no sólo una traducción» ${ }^{13}$. Si lo hacemos mal, son gajes del oficio, pero si lo hacemos especialmente bien, entonces es que ni siquiera somos traductores dignos de tal nombre. Como se puede ver, es cosa de locos y haga uno lo que haga, está condenado al fracaso. En cierto modo, la idea de la condena a la imperfección constituye algo muy humano, pero no deja de ser irritante que sólo se aplique de forma sistemática a los traductores.

Sin embargo, algo que no se suele tener en cuenta es que los autores de los originales también son humanos y, por tanto, falibles. Cualquier traductor, especialmente los que tengan experiencia en el procesamiento de textos científico-técnicos, sabe esto perfectamente (cf. por ejemplo Berglund ${ }^{14}$ o Schofield ${ }^{15}$ ). De hecho, uno de los

\footnotetext{
13 Traducción mía.

14 Lars O. Berglund, «The Search for Social Significance», Lebende Sprachen 35, 4 (1990): 145-151.

15 David W. Schofield, «Interactive-Back-Translation with Writers of their Translated Manuscripts of Original Research in Medicine and Science for Publication in International Learned Journals: A Creative Process that Improves Informative Content and Presentation», Leandro Félix Fernández y Emilio Ortega Arjonilla (eds.) Traducción e interpretación en el ámbito biosanitario (Granada: Comares, 1998) 233-250.
} 
problemas habituales del traductor de manuscritos destinados a revistas internacionales consiste no tanto en acercarse a la altura del original, sino en conseguir que el texto traducido no caiga en los mismos errores, normalmente de carácter estilístico, aunque también en ocasiones terminológico. La razón es bien simple: por su formación, los autores de este tipo de manuscritos son en su mayoría expertos en el área temática correspondiente, pero en absoluto expertos en las artes comunicativas de la redacción de textos.

Esto lleva a la cuestión de la misión o escopo del traductor de textos científico-técnicos y, más concretamente, a la legitimidad de introducir en la traducción cambios deliberados con la intención de mejorar el resultado final. La perspectiva previa a los estudios de traducción modernos diría básicamente que el deber del traductor consiste en «limitarse» a traducir, es decir, reproducir el texto original con la máxima fidelidad posible, signifique eso lo que signifique. Si el objetivo es la fidelidad, cabe suponer que esta incluye reproducir fielmente los errores y ambigüedades del original. Como se oye decir a los alumnos de vez en cuando, «yo sólo soy el traductor y si se entiende mal, no es culpa mía, sino del autor, porque ya estaba así en el original».

La teoría de la traducción moderna, sin embargo, plantea que la labor del traductor es mucho más compleja de lo que pueda parecer a primera vista y se ve sometida a más de una lealtad. Ampliando la idea de doble tensión de Toury que antes mencionábamos, autores como Nord plantean que la lealtad del traductor en realidad es triple: hacia el texto original y su autor, ciertamente, pero también hacia el cliente y hacia el lector. Otros como Kiraly añaden a estas tres lealtades una cuarta, hacia la propia ética y concepto de la traducción que tenga el traductor. Como no podía ser de otro modo, este conjunto de lealtades entra en conflicto entre sí con frecuencia y el traductor se ve obligado a negociar y establecer prioridades para cada situación. Por ilustrarlo con un ejemplo simple y muy real que me sucedió a mí hace unos años, ¿qué hacer si nos encargan traducir una entrada enciclopédica en la que la ciudad libanesa de Tiro en la versión original inglesa está 
situada en Palestina? Una visión tradicional de la traducción me empujaría a dejarla tal cual o a pedir permiso al autor original antes de realizar cualquier cambio. Sin embargo, la traducción debía entregarse en dos días y el traductor no tenía ninguna vía de contacto directo con el autor, que además era anónimo al tratarse de una entrada enciclopédica. Claramente, la lealtad hacia el texto original y hacia el cliente entraban directamente en conflicto. ¿Qué hacer entonces?

Para abordar esta cuestión, resulta fundamental considerar que los científico-técnicos constituyen textos esencialmente referenciales o informativos con una faceta persuasiva. Son, por tanto, textos en los que la presencia y la voluntad estilística del autor ocupan un plano claramente secundario y en los que la veracidad, precisión y claridad constituyen valores habitualmente supremos. Dicho de otro modo, normalmente uno no traduce este tipo de textos, especialmente los técnicos, con la idea de transmitir ante todo la visión del mundo del autor en sus propios términos -como sí sucede con frecuencia en literatura-. Por el contrario, la eficacia de la información que se transmite constituye con toda probabilidad el valor supremo en la gran mayoría de los casos.

Si el autor original lo ha conseguido, bien está y nuestra labor consistirá en mostrarnos a su altura teniendo muy en cuenta las nuevas circunstancias de recepción. ¿Pero qué hacer cuando el original presenta expresiones ambiguas, sintaxis fallida o sinonimia terminológica injustificada, por mencionar los tres problemas de calidad más habituales en este tipo de textos?

El ejemplo de Tiro no es excepcional. Resulta típica la situación en la que un sociólogo, ingeniero o médico quiere publicar un artículo en inglés en una revista extranjera y nos entrega un manuscrito en español que presenta el tipo de errores que acabo de mencionar. Podemos esforzarnos por hacerlo igual de mal para no perder el título de traductores según explicaba la Encyclopaedia Britannica, aún sabiendo que hacerlo así será probablemente causa del rechazo del manuscrito en la revista de destino. O podemos esforzarnos por producir un artículo 
bien escrito en el nuevo idioma — es decir, mejor que el original-, con el fin de contribuir a su aceptación. Los análisis terminológicos no nos ayudarán demasiado en este apuro, ya que nos servirán como mucho para saber cómo conseguir producir términos adecuados en el nuevo idioma, pero ese no es nuestro verdadero problema.

Por lo que sé, la práctica totalidad de los traductores de este tipo de textos optarán por la mejora del original, consciente o inconsciente. Limitar la labor del traductor a intentar reproducir el original, incluidos posibles errores del mismo, sería prestar un flaco servicio tanto al cliente como a los destinatarios. Resulta más que razonable suponer que el especialista que nos encarga una traducción se hallará bastante más interesado en la calidad del producto final que en el «escrupuloso respeto» a su (in)capacidad estilística o a sus errores terminológicos o incluso factuales. Una respuesta de la revista destinataria rechazando el artículo por problemas de redacción no será fácilmente solventada por el traductor que aduzca ante el cliente que el original ya era defectuoso y, por tanto, se ha limitado a intentar hacerlo «igual de mal». Del mismo modo, si nos piden que traduzcamos una entrada enciclopédica y nos encontramos con una fecha errónea o un topónimo mal ubicado en el mapa, el traductor eficiente será con toda probabilidad el que detecte esos errores y los corrija, no el que los transmita tal cual al nuevo lector. Por poner un último ejemplo más evidente aún, si un manual de instrucciones original está redactado de tal modo que el usuario corre algún peligro, parece obvio que las lealtades del traductor le llevarán a dar prioridad a sus deberes hacia el usuario final y, por tanto evitar que su lector se electrocute, aunque ello suponga enmendarle la plana al autor original.

\section{Conclusiones}

La ciencia terminológica constituye un instrumento de ayuda esencial para la traducción científico-técnica, pero por las razones antes expuestas, esta actividad precisa de consideraciones que van 
mucho más allá de cómo producir terminología correcta o cómo reproducirla en condiciones ideales y ajenas a las pulsiones sociales en el otro idioma. Como hemos tratado de mostrar, la traducción - también la de textos científico-técnicos- constituye una actividad compleja en la que se deben contemplar consideraciones de carácter estilístico y cultural que trascienden a la terminología. Cuestiones como la manera de abordar la interferencia basándonos en un profundo conocimiento de sus causas y los usos sociales de los especialistas o la posible mejora de los originales requieren análisis culturales, antropológicos e incluso filosóficos que van más allá de la lingüística general y aplicada.

Los estudios de traducción tienen mucho que aportar al traductor necesitado de explicar a los demás y a sí mismo por qué actúa de una manera determinada. Con su cuestionamiento y profundización de la realidad, es la teoría la que proporciona pistas y argumentos que permiten entender mejor lo que hacemos los traductores. Más aún, ese «abrir los ojos» que constituye la función primordial de la teoría, nos permite también salir de lo que de otro modo sería un comportamiento mecánico y empezar a ser dueños de nuestros actos. Ciertamente, ese conocimiento y esa conciencia de uno mismo tienen un precio, que podríamos describir como la problematización de nuestro mundo, que de repente se vuelve más complicado que la mera búsqueda de supuestos equivalentes terminológicos prefijados. A cada traductor le corresponde decidir si está dispuesto a pagar el precio de la duda sistemática a cambio de un mayor conocimiento de símismo. 